\title{
AS TICS NA ESCOLA: DESAFIOS PARA A AÇÃO E FORMAÇÃO DOCENTE
}

Thiago Soares Valentim Grass

Pedagogo e Prof. Especialista Parceiro da Universidade São Judas

\section{RESUMO}

Este trabalho tem por objetivo averiguar de que forma o surgimento e evolução das Tecnologias da Informação e Comunicação na Educação Básica impactaram a função do professor. Além disso, explora como esses recursos tecnológicos influenciaram os cursos de formação de professores. As linguagens e aparatos digitais são uma realidade na vida contemporânea e discutir sua influência no campo da Educação é de suma relevância. Para isso, utilizou-se de pesquisa bibliográfica das principais fontes sobre o tema. Depois desse estudo, percebeu-se a importância do surgimento das TICs no contexto educacional no campo metodológico e formativo do professor.

Palavras-Chave: TICs, Docência, Formação. 


\section{1- INTRODUÇÃO}

As tecnologias da informação e comunicação (TICs) transformaram a vida contemporânea. Modificaram contundentemente a forma como as relações sociais e profissionais acontecem e se desenvolvem no cotidiano. Diversos recursos novos são lançados em espaços de tempos cada vez menores. Uma infinidade de ferramentas são colocadas à disposição.

A escola, como lugar responsável por propiciar à criança o contato com o conhecimento historicamente acumulado pelo homem, não pode ficar à margem dessas transformações tecnológicas e informacionais. Ela precisa se agregar com essas formas de interação propiciadas pelas linguagens digitais, assim como o professor.

Como grande mediador da aprendizagem na escola, o docente precisa estar atento a esses recursos que possibilitam novas metodologias. Ele deve se permitir praticar novos olhares para caminhos pedagógicos antes improváveis. O que denota a importância da sua formação nesse processo. Diante disso, situa-se a seguinte questão: quais as implicações que as TICs trazem para os cursos de formação de professores?

A princípio, acredita-se que as TICs ocasionaram uma mudança significativa nas metodologias de ensino-aprendizagem nos cursos de licenciaturas do Ensino Superior. As Universidades buscaram evoluir para se adequar ao novo contexto, porém, talvez não de modo satisfatório quanto à formação de novos professores aptos para atuar nessas linguagens contemporâneas.

Dessa forma, este trabalho tem o objetivo de verificar as consequências do surgimento e evolução das TICs na Educação Básica para o docente. Pretende também investigar de que forma esses recursos tecnológicos influenciaram os cursos de formação de professores.

Assim, esse estudo foi organizado por meio de pesquisa bibliográfica de fontes relevantes sobre a temática. Para começar, define o que são TICs e como se integraram ao contexto contemporâneo, chegando à escola básica e influenciando a prática docente. Em seguida, traz as implicações que as TICs trouxeram aos cursos de formação de professores.

\section{2- REFERENCIAL TEÓRICO}

\section{2-1 AS TICS NA ESCOLA BÁSICA DA ATUALIDADE}

A tecnologias são tão antigas quanto o próprio homem. Água, pedra e fogo, por exemplo, já foram considerados ferramentas tecnológicas. Tecnologia sempre foi sinônimo de poder. E desde o início, sempre considerada um fruto da engenhosidade humana, que deu origem a um processo crescente de inovações nesse campo. 
O próprio avanço científico da humanidade possibilita o conhecimento desses recursos tecnológicos já existentes e a criação de novas tecnologias cada vez mais amplas e sofisticadas. E essa evolução não se restringe a usos de equipamentos e produtos específicos. "A ampliação e a banalização do uso de determinada tecnologia impõem-se à cultura existente e transformam não apenas o comportamento individual, mas de todo o grupo social" (KENSKI, 2015, p.21).

No contexto contemporâneo, as Tecnologias da Informação e Comunicação (TICs) produziram e vêm produzindo mudanças na sociedade. Esse processo se intensificou nas últimas décadas a ponto de torná-las a base sobre a qual se desenvolvem as principais atividades humanas e sociais. Piletti (2013, p.120) conceitua essas novas TICs:

[...] definidas como um conjunto de recursos tecnológicos, os quais, usados de modo integrado, reúnem, transmitem, distribuem e compartilham informações através de textos, imagens, vídeos e sons, proporcionando a automação e comunicação de vários tipos de processos existentes.

A inserção dessas novas tecnologias ocorre de forma rápida e intensa. Em determinado momento elas se oferecem, são integradas e pouco tempo depois descartadas, substituídas por um novo recurso, mais poderoso, abrangente e diferente. Essas mudanças trazidas pelos meios digitais transformaram a cultura de forma geral.

Kenski (2013) destaca que o acesso aberto à internet a partir de meados dos anos 1990 foi o ponto de partida para esse processo de valorização das tecnologias digitais em todos os setores da sociedade, inclusive na educação.

Nesse contexto, não é mais o indivíduo que sai em busca de informações, é a informação que se oferece sem ser buscada, surpreendendo e o acompanhando em todos os momentos, todos os dias. "Informação fácil sobre tudo, que invade a nossa privacidade, ocupa o nosso tempo e o espaço do nosso pensamento, transforma nossas intenções, manipula nossos desejos" (KENSKI, 2013, p.86).

A base dessa linguagem digital são os hipertextos. Uma série de camadas de documentos interligados que funcionam como páginas sem número e que podem ser lidas sem uma sequência específica e conectados por links. O hipertexto é uma evolução do texto linear na forma como o conhecemos. "Se no meio desse encadeamento de textos houver outras mídias - fotos, vídeos, sons etc. - o que se tem é um documento ou, como é mais conhecido, uma hipermídia” (KENSKI, 2015, p.32).

Com a hipermídia, se acessa a informação em uma variedade enorme de formatos. Dessa forma, a linguagem digital impõe uma mudança radical nas formas de acesso à informação, ao entretenimento e à própria cultura. Baseada no acesso à computadores e smartphones, à internet, aos jogos eletrônicos em rede, à convergência de mídias, influencia cada vez mais a constituição de atitudes, valores e conhecimentos.

Segundo Brito e Purificação (2012), todo esse movimento atingiu a educação em meados dos anos 1970, de forma mais abrangente no setor administrativo das escolas. A implantação de 
projetos de informática teve uma ascendência nos anos 1990, com a tentativa de promover na escola básica o acesso aos conteúdos digitais disponíveis (que ainda engatinhavam).

Isso porque a internet foi liberada para exploração comercial a quem interessasse no Brasil somente em 1995. Em comparação, o mesmo ocorreu nos EUA em 1969. "A internet veio para mexer com os dogmas educacionais, em que não cabem mais arbitrariedade de opiniões, linearidade de pensamento, um único caminho a ser trilhado" (BRITO; PURIFICAÇÃO, 2012, p.115).

O desenvolvimento da tecnologia atinge a sociedade de tal forma que a escola não pode ficar alheia à essa mudança. Ela representa o espaço de formação que possibilita o domínio de conhecimentos.

O papel da escola como dispositivo de inclusão e democratização do saber é extremamente importante, fundamental para a formação de usuários competentes, criativos e críticos (distanciados), capazes de colocar as TICs a serviço da criatividade humana e da solidariedade social (BELLONI, 2014, p.123).

Mas essa missão configura-se em um verdadeiro desafio. A criança hoje não se encontra mais em uma postura passiva. Antes mesmo da sua entrada na educação formal, ela tem contato com esses recursos tecnológicos. Ela é um indivíduo multitarefa, estando em uma zona de convergência total com as linguagens e aplicações digitais. Acessa a internet, baixa e transfere arquivos pelo celular, fotografa entre outras coisas.

"As tecnologias não são o fim da aprendizagem, mas um meio profícuo para que se possam efetivar novas propostas metodológicas que levem o aluno a "aprender a aprender" (HILU; TORRES, 2014, p.191). Isso leva à necessidade de adoção de novos meios de formação e escolarização diante desses emergentes padrões de comportamento e relacionamentos sociais e pessoais produzidos pelas TICs.

Já não se pode falar de um novo simples recurso incorporado à sala de aula, mas de algo que modifica e perpassa inclusive os espaços físicos em que a educação acontece. Não existe dúvidas de que as TICs trouxeram alterações consideráveis e positivas na educação. Onde imperavam somente o giz, a lousa e o livro didático agora encontram-se também vídeos, programas educativos, computador, sites e softwares educacionais, jogos entre outros.

Entretanto, a escola precisa aceitar essa nova demanda. É preciso que surja uma nova escola, que encare o desafio da mudança e atenda às necessidades de formação e treinamento nesse novo cenário.

Pensar o computador na escola não significa somente pensar na ferramenta, mas nos processos e práticas pedagógicas que ele pode propiciar com a mediação dos professores. Quando articuladas aos conhecimentos escolares, as tecnologias propiciam práticas pedagógicas interessantes e motivadoras para esses últimos, contribuindo com seu envolvimento na produção do conhecimento (PORTO, 2013, p.186). 
Portanto, é crucial que o professor da atualidade esteja com o olhar voltado para o presente, mas visando o futuro nessa nova realidade que se apresenta. Assim, escola e professor precisam se atualizar e agregar os novos paradigmas da contemporaneidade na educação. Deve existir sintonia com tais perspectivas e desafios impostos pela cultura digital.

Especificamente, os professores devem se instrumentalizar no exercício de sua profissão, de modo a incorporarem os usos tecnológicos e metodológicos da contemporaneidade, porém compreendendo-se como um integrante de um processo maior cultural e social e vivenciando-o plenamente (HILU; TORRES, 2014, p.177).

A tecnologia não é somente um instrumento, ela é uma extensão do próprio aluno. Novas tendências vão surgindo, entre elas a aprendizagem online, a híbrida além de modelos cooperativos. Elas são fruto da forma como se dá a comunicação, do acesso à informação e da própria mudança na socialização.

A proposta pedagógica adequada a esses novos tempos precisa ser não mais a de reter em si a informação. Novos encaminhamentos e novas posturas nos orientam para a utilização de mecanismos de filtragem, seleção crítica, reflexão coletiva e dialogada sobre os focos de nossa atenção e a busca da informação (KENSKI, 2013, p.87).

Essa relação de mediação entre alunos e professores é fundamental para que se possa diferenciar, em meio à imensa gama de informação disponível, o que de fato pode ser útil para um aprendizado significativo, permanecendo assim para toda a vida. As TICs e o ciberespaço são novos elementos pedagógicos que oferecem grandes possibilidades.

Contudo, é necessário que o docente saiba trabalhar com essas mudanças e as incorpore na sua prática cotidiana. "Professores bem formados conseguem ter segurança para administrar a diversidade de seus alunos e, junto com eles, aproveitar o progresso e as experiências de uns e garantir, ao mesmo tempo, o acesso e uso criterioso das tecnologias pelos outros (KENSKI, 2015, p.103).

O que nos leva à questão a respeito da formação docente e as grades curriculares dos cursos de licenciatura. Pois, para formar um profissional integrado com o contexto tecnológico e digital, é necessário que haja um olhar atento à essas mudanças.

\section{2-2 E A FORMAÇÃO DO PROFESSOR?}

Diante das atuais demandas e pensando na formação de professores, as TICs possuem um papel preponderante. Elas podem contribuir de inúmeras formas, principalmente no que diz respeito ao desenvolvimento de metodologias inovadoras e ao uso dos diversos recursos tecnológicos disponíveis. 
Os conhecimentos adquiridos nos cursos de formação (inicial/continuada) precisam imprimir em seus discentes características de uma formação que busque a teorização acadêmica, a criticidade, a reflexão sobre sua prática, a pesquisa como possibilidade para novos conhecimentos teórico-práticos diante dos enfrentamentos que a docência enfrenta na contemporaneidade (FERREIRA, 2014, p.40).

Portanto, não há como negar que esse poder tecnológico e comunicacional reflete na educação e facilita a formação de professores. Torres (2004) ressalta e defende a importância das tecnologias nesse processo de construção do futuro docente, sendo essencial que a universidade converta com agilidade em conteúdos e recursos para a formação os novos conhecimentos que a ciência e a tecnologia produzem.

Meios digitais e atuação pedagógica, seriam dessa forma, duas partes que se fundem em uma oferecendo metodologias de ensino criativas, participativas e inovadoras. Kenski (2013), contudo, faz ressalvas, pois o processo de ensino não se articulou com o avanço tecnológico assim como as propostas curriculares e a própria formação de professores e ainda completa:

Formar professores com qualidade e conhecimento teórico e prático para atuar em múltiplas frentes, além dos espaços tradicionais da educação regular - como educação à distância; educação mediada pelas tecnologias; educação cooperativa, empreendedora inclusiva etc. -, é uma necessidade que a nova cultura e a nova sociedade exigem (p.91).

A importância desses componentes e linguagens digitais no processo de formação docente e de ensino-aprendizagem no ambiente escolar está dada. Um movimento que se iniciou em 1995 com a estruturação de disciplinas de Informática na Educação, que posteriormente começou a integrar os currículos das universidades brasileiras em cursos de Pedagogia e de licenciaturas (BRITO; PURIFICAÇÃO, 2012).

Todavia, Gatti e Barreto (2009) trazem outro dado preocupante nesse sentido. Essas autoras salientam a insuficiência de disciplinas sobre tecnologias nos vários cursos de licenciaturas no Brasil. Elas informam que nos cursos de Pedagogia, por exemplo, sua presença representa apenas $0,7 \%$ das disciplinas obrigatórias e 3,2\% das disciplinas optativas.

Essas linguagens emergentes oriundas da evolução tecnológica produzem formas distintas de interação e precisam ser problematizadas no currículo de formação de professores. Universidades, escola e o professor não podem ignorá-las. Esses novos jeitos de expressar e comunicar também se tornam condições para a cidadania participativa e crítica.

Por mais que se esteja em um nível tecnológico antes nunca visto, a escola não desapareceu, nem deixou de ter importância. Pelo contrário, seu papel fica mais claro e evidente. Ela permanece, transformando suas ações e meios de interação entre pessoas e conteúdos, sendo essencial para o projeto de qualquer proposta de sociedade.

"A escola não se acaba por conta das tecnologias. As tecnologias são oportunidades aproveitadas pela escola para impulsionar a educação, de acordo com as necessidades sociais de cada época" (KENSKI, 2015, p.101). A missão, assim, passa a ser inventar e explorar 
meios criativos da tecnologia educacional que estimulem professores e alunos a gostarem de aprender.

Cabe dizer, depois desse cenário, que a situação "professor versus tecnologia" não tem mais espaço nas escolas e na educação de forma geral. É preciso fortalecer, portanto, a formação tecnológica nas licenciaturas. Pois, assim como a escola básica, as universidades também não podem renegar essa evolução tecnológica.

\section{3- METODOLOGIA}

O presente artigo utiliza pesquisa bibliográfica exploratória como premissa para discutir o tema das Tecnologias da Informação e Comunicação (TICs) na Educação Básica e as implicações desse movimento para a atuação docente e para os cursos de licenciatura.

Mascarenhas (2012) ressalta a importância desse tipo de metodologia ao oferecer uma gama impressionante de informação, porque, quando se decide por determinado caminho, é necessário ver o que já foi dito sobre ele.

O foco desse estudo foi investigar a relação entre o surgimento e expansão das TICs na Escola, nos anos iniciais, e o papel do docente nesse processo, sem esquecer dos cursos de formação de professores. Isso não exclui, no entanto, a descoberta de novas hipóteses e questões ligadas ao tema.

\section{CONSIDERAÇÕES FINAIS}

Depois desse estudo fica evidente que o surgimento das TICs e a sua introdução no campo da Educação Básica acarretou mudanças significativas no trabalho do professor que atua nos anos iniciais. Isso não quer dizer que giz e lousa estão extintos, mas não são mais os únicos protagonistas.

As TICs trouxeram, trazem, e certamente ainda trarão muitos elementos que vão mudar a percepção do processo de ensino-aprendizagem na escola, alçando-o a um patamar diferenciado em constante evolução. O que significa que escola e professor precisam estar sempre atualizados com os recursos disponíveis que surgem em intervalos de tempos cada vez mais curtos.

Não cabe mais ao professor evitar ou hostilizar essa onda tecnológica e informacional. Renegar o trabalho com as TICs é desperdiçar oportunidades de aprendizagem significativa com os alunos, é perder chances de trilhar caminhos diferentes do ensino com metodologias diferenciadas. 
É necessário ao docente encarar esse cenário tecnológico como positivo, como uma linguagem capaz de modificar de forma expressiva o trabalho cotidiano. Isso demanda, porém, um processo de formação continuada constante. Formação que deve garantir preparo e vivência com as plataformas e recursos digitais.

Essa transformação tecnológica na sociedade, que atinge a escola e o próprio cotidiano do profissional também traz consequências nos cursos de licenciatura do Ensino Superior. É preciso que as Universidades invistam nas disciplinas ligadas às TICs para oferecer um suporte teórico mais próximo da prática.

É evidente que muito do que a escola e o professor podem oferecer de ação baseada nas TICs depende de investimentos do setor público. Embora tal questão não tenha sido explorada neste trabalho, ela é relevante e merece destaque em estudos futuros. As TICs na educação são uma realidade. 


\section{BIBLIOGRAFIA}

BELLONI, Maria Luiza. Crianças e mídias no Brasil; cenários de mudança [livro eletrônico]. Campinas: Papirus, 2014.

BRITO, Glaucia da Silva; PURIFICAÇÂO, Ivonélia da. Educação e novas tecnologias: um (re)pensar [livro eletrônico]. Curitiba: Intersaberes, 2012.

FERREIRA, Jacques de Lima. A complexa relação entre teoria e prática pedagógica na formação de professores. In: In: FERREIRA, Jacques de Lima (org.). Formação de professores: teoria e prática pedagógica. Petrópolis: Vozes, 2014, p.33-49.

GATTI, B.; BARRETO, E. S. Professores do Brasil: Impasses e desafios. Brasília: Unesco, 2009.

HILU, Luciane; TORRES, Patrícia Lupion. Tecnologias emergentes na educação. In: FERREIRA, Jacques de Lima (org.). Formação de professores: teoria e prática pedagógica. Petrópolis: Vozes, 2014, p.171-191.

KENSKI, Vani Moreira. Tecnologias e o tempo docente [livro eletrônico]. Campinas: Papirus, 2013

Educação e Tecnologias: o novo ritmo da informação [livro eletrônico]. Campinas: Papirus, 2015.

MASCARENHAS, Sidnei Augusto (org.). Metodologia científica. São Paulo: Pearson Education do Brasil, 2012.

PILETTI, Nelson. Aprendizagem: teoria e prática. São Paulo: Contexto, 2013.

PORTO, Tania Maria E. As tecnologias estão nas escolas. E agora, o que fazer com elas?. In: FANTIN, Monica; RIVOLTELLA, Pier Cesare. Cultura digital e escola: pesquisa e formação de professores [livro eletrônico]. Campinas: Papirus, 2013, p.167-194.

TORRES, P. I. Laboratório online de aprendizagem: uma proposta crítica de aprendizagem colaborativa para a educação. Tubarão: Unisul, 2004. 